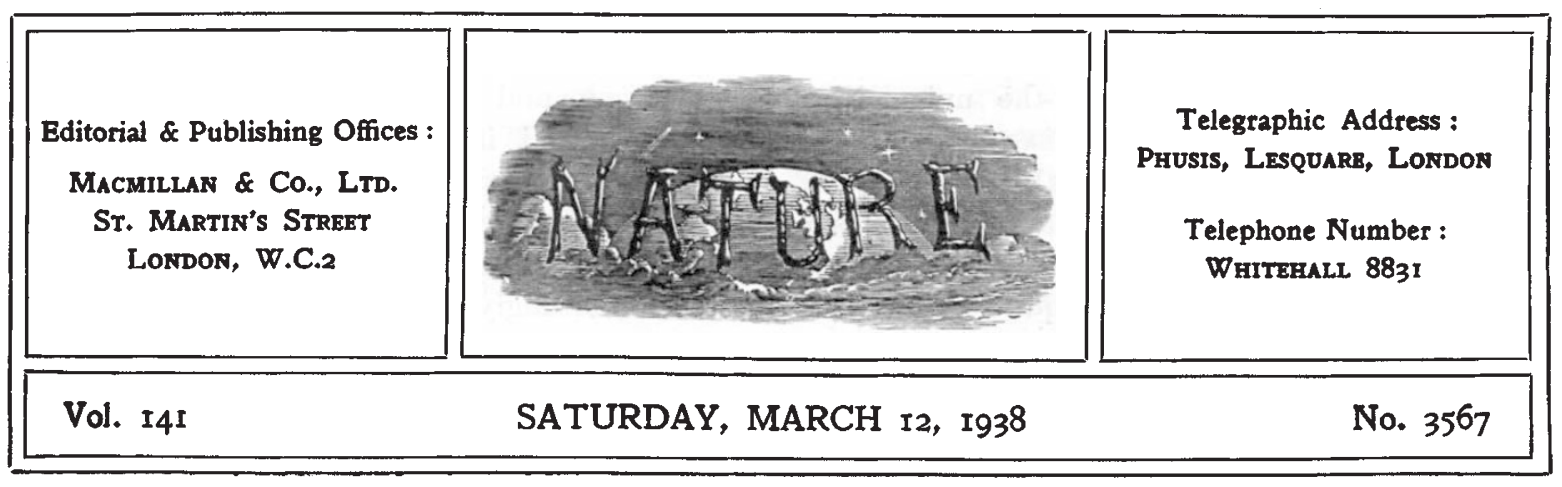

\title{
Interpretation and Exposition of Scientific Research
}

$\mathrm{O}^{\mathrm{N}}$ $\mathrm{NE}$ of the most important tasks of the Department of Scientific and Industrial Research, in the view of the Advisory Council, as indicated in the report of the Department for 1936-37, a summary account of which appears on p. 432 , is to organize the conduct of research so as to promote contact with industry. Particular attention is given to this question of contact with industry in a number of the recent reports of the Advisory Council, and one reason for attaching importance to the development of the research association movement is the opportunity it affords for the industrialist to state his problems to the man of science and to determine the order of priority, in terms of their economic importance, of the objectives of particular proposals for research.

The success of the Department in fostering cooperation with an even wider range of industries and interests than is represented by the research associations is well illustrated by the work of the Water Pollution Research Board, the first ten years' work of which is reviewed in some detail in the latest report of the Advisory Council. In spite, however, of all that the Department has done to promote the application of results by industry, British industry still appears to lag behind industry in the United States.

Special attention is directed to this point by the Advisory Council in commenting upon a visit paid last year to Great Britain by a party of some thirty American business men and bankers who came to take stock of the conditions under which research is carried out here, and of the organization adopted to promote the practical application of its results. The visit was organized by the Division of Engineering and Industrial Research of the
National Research Council of America, and after spending a fortnight in England the visitors proceeded to France and then to Germany, where they made similar inquiries. In Great Britain, the arrangements for visiting laboratories were made in close co-operation with the Department of Scientific and Industrial Research. The strenuous programme included visits to the Science Museum, the National Physical Laboratory, the Fuel Research Station, the Building Research, the laboratories of four research associations and of five representative industrial corporations as well as to the Cavendish Laboratory, Cambridge.

The tour was arranged primarily for the information of business men and bankers whose chief interest in the laboratories they visited was the utilitarian requirements of commerce and finance. The tour provided a striking object lesson in the keenness of industrial management in the United States to ensure that no opportunity is lost of turning science to the advantage of its business, and in commenting on the tour the Advisory Council refers to the necessity in Great Britain of giving more attention to the presentation of the progress of industrial research to what are described in the United States as the executives of business. What is here required is the presentation, not so much of scientific data, as of their industrial and financial implications, and in reviewing the various aspects of the publication policy pursued by the Department, the Advisory Council raises again the question of the interpretation of the results of scientific research which has an ever-growing importance.

A first objective in the publication policy of the 
Department is, of course, the provision of the full scientific data of the researches carried out so that the technical man can judge of their value for himself and apply them in his own industry. To a large extent, this need is already admirably served by special reports published on behalf of the Department by H.M. Stationery Office, as well as by papers read before the learned and technical societies and by special articles contributed to technical and trade journals. Indeed, many of the reports and papers emanating from the Department set an admirable example of lucidity of exposition which could be followed with advantage by other scientific workers in presenting the results of their work.

Increasing attention is being paid by the technical Press to the activities of the Department, and this not only in itself promotes the dissemination of the reports themselves but also provides one means of presenting the work to the executive leaders of industry. There can be no doubt that in the last fow years the interest of the general Press in scientific news has greatly increased, and already in the United States of America Science Service has been developed to render expert assistance to the Press in this field and particularly to overcome some of the difficulties encountered in presenting scientific news in a form which can be understood by the public.

Industrial research has its own special difficulties in this matter. The germ of an industrial advance is usually found in a discovery in the laboratory, but its development and final applications to industry may take a long time. Great caution is accordingly always necessary in the presentation of the initial discoveries before their industrial applications have been explored and tested. Apart from the hampering effect of premature disclosure on technical development, which is often much less serious than is supposed, unfulfilled prophecies are themselves liable to be detrimental to the general application of research. On the other hand, when the necessary reserve and caution are used in announcing the early stages of some new work the result often makes dull reading whether to the business executive or to the man in the street.

For these reasons, the Advisory Council attaches more importance to the fact that the Press is doing its utmost to stress the value of research in national development. It should be obvious, however, that the tasks of presenting results to business executives and also to the ordinary tax-payer, who provides the major part of the Department's expenditure and has every right to be told how the results are of benefit to him and to the nation as a whole, are by no means identical. For both purposes, the results must be expressed in nontechnical language, but the content and emphasis required in the exposition are very different.

We have here a problem to which scientific workers, whether in industry or not, might well give more attention. Nor is it a problem for them alone. Fundamentally, it is one of co-operation between the technical or scientific worker and the Press, only to be solved as mutual understanding and respect are established. Although the Press in Great Britain has not moved anything like so far in the utilization of scientific men for the collection and editing of news as in the United States, and generally gives less care and thought to the presentation and accuracy of scientific news than to most other specialized activities, generally speaking it is much more alive than formerly alike to the significance and importance of scientific work and to the difficulties in the way of its accurate exposition or interpretation. In fact the first need to-day is probably for a greater response and willingness to co-operate on the part of the scientific worker himself.

Much is indeed involved in such co-operation. In the first place, there is still far too much jargon and loose expression in scientific or technical papers. It is true, of course, that the scientific investigator is entitled to use the same vocabulary as other workers in the same field when addressing himself to a scientific society, but unfortunately insufficient care is often taken in regard to the introduction of new terms even here. Moreover, many scientific workers are guilty of confused thinking and want of care in arranging their ideas in logical sequence or in expressing them concisely.

Such careless writing places difficulties in the way of the appraisement or evaluation of the work of the scientific investigator by his own colleagues and still more in its interpretation to the nontechnical man or general public. The scientific worker has to remember that his work has not fully achieved its purpose until it is understood and can be integrated into the general body of knowledge of the science or industry.

This in turn demands from the scientific worker not only a much greater respect for accurate and lucid writing, and more whole-hearted attempts to see that the careless use of words does not invalidate accurate and painstaking experimental 
work but also an appreciation of the position and work of the expositor and in particular of the work which the Press is trying to do. High ability in research and felicity of exposition are by no means always linked in the same person, and investigator and expositor have each their place to fill and merit their own reward. The lack of regard of scientific men for some of the ablest expositors in their own ranks is probably one reason why science is not so widely and well served in that respect as is desirable.

If most scientific workers have little desire or capacity to transform the special vocabularies of their subjects into the simpler and not necessarily sensational forms required by the general reader, remembering these things, they should be more grateful for the service rendered to science itself by those who are able to present a scientific subject accurately and attractively in a literary style.

Fundamentally, therefore, this question of publication turns on education, both that of the man of science in the capacity to express himself in terse and lucid English, and that of the general member of the public, whether of the Press or not, so that he has a general scientific background against which to set scientific or technical progress as it is made known. Both aspects are of importance, but it would be a mistake to imagine that the printed word is the only means by which the results of scientific work can be brought before the community.

One such method is seen in exhibitions organized by the Department of Scientific and Industrial Research to show the results of its research. Already a number of such exhibits has been arranged : at the Smoke Abatement Exhibition in the Science Museum, at the Public Health Exhibition in the Royal Agricultural Hall, at the Engineering Exhibition in Greyfriars Hall, Cardiff, at the Building Centre and at the Exhibition of Testing Plant and Apparatus at the Institution of Civil Engineers and at the Engineering and Marine Exhibition. The Advisory Council considers that this activity provides an excellent means of forming contacts between the staff of the Department and those engaged in industry, and assists in making better known the facilities available in the Department for co-operative research and for dealing with special inquiries.

The method is of course already in use by many industrial firms both in connexion with their technical service work and to make known the results and scope of their research, as in that recently organized by Imperial Chemical Industries Ltd., in connexion with the opening of the new research laboratories at Blackley, Manchester. Other examples are to be found in the special exhibits arranged at the Science Museum and elsewhere, and the success they have achieved indicates that exhibits of this type offer a very valuable means of bringing the results of scientific and industrial research before the general community.

In connexion with the preparation for exhibits, the Department of Scientific and Industrial Research has recently begun to make short films dealing with the work. These films have already proved of great value in illustrating lectures given all over the country by officers of the Department and they are in some demand by technical societies. Here again is a medium of education and exposition to which scientific workers might well give more attention, while the series of talks which from time to time have been broadcast under such titles as "What more do you want of the scientist?" or Dr. Julian Huxley's talks on scientific research and social needs indicate yet another medium which science itself has placed at their disposal.

The reference to these matters in the Advisory Council's report is the more welcome bezause the lack of unity in the profession of science makes it difficult to utilize the opportunities of interpretation and exposition which are in these ways offered to the world of science. The Department indeed is probably in almost a unique position in its capacity and ability to interpret to the world of industry and to the community generally the results of both pure and applied scientific research. Already its publications indicate an attention to the art of exposition and interpretation which are seldom elsewhere paralleled in the scientific world, except in the technical publications issued by the publicity departments of a number of our more progressive industrial firms-publications themselves insufficiently appreciated by scientific workers. With a little more support and co-operation from scientific workers generally it should not be impossible for the Department to explore even more widely the possibilities not only of publications but also of such other media as exhibitions, the film or the broxdcast talk in interpreting to the ordinary citizen the significance and meaning of the achievements of scientific and technical research. At least it may be hoped that the latest report of the Advisory Council will again direct the attention of scientific workers to a question which has far too often been neglected or disdained. 